\title{
THEORETICAL STUDY OF HEAT TRANSFER EFFECTS ON FLOW PAST A PARABOLIC STARTED VERTICAL PLATE IN THE PRESENCE OF CHEMICAL REACTION OF FIRST ORDER
}

\author{
R. MUTHUCUMARASWAMY* \\ Deparment of Applied Mathematics \\ Sri Venkateswara College of Engineering \\ Pennalur, Irungattukottai 602117 (Sriperumbudur Taluk), INDIA \\ E-mail: msamy@svce.ac.in \\ S. VELMURUGAN \\ Department of Mathematics \\ Madha Institute of Engineering and Technology \\ Errandamkattalai, Sadanandapuram \\ Thandalam Post, Chennai 600122, INDIA
}

\begin{abstract}
An exact solution of an unsteady flow past a parabolic starting motion of an infinite vertical plate with variable temperature and mass diffusion, in the presence of a homogeneous chemical reaction of first order has been studied. The plate temperature as well as concentration level near the plate are raised linearly with time $t$. The dimensionless governing equations are solved using the Laplace-transform technique. The effects of velocity profiles are studied for different physical parameters such as the chemical reaction parameter, thermal Grashof number, mass Grashof number, Schmidt number and time. It is observed that the velocity increases with increasing values of the thermal Grashof number or mass Grashof number. The trend is just reversed with respect to the chemical reaction parameter.
\end{abstract}

Key words: parabolic, homogeneous, chemical reaction, first order, vertical plate, heat and mass transfer.

\section{Introduction}

Chemical reactions can be divided into two groups. They are (i) homogeneous and (ii) heterogeneous. This depends on whether they occur at an interface or as a single phase volume reaction. In well-mixed systems, the reaction is heterogeneous, if it takes place at an interface and homogeneous, if it takes place in solution. In most cases of chemical reactions, the reaction rate depends on the concentration of the species itself. A reaction is said to be of first order, if the rate of reaction is directly proportional to the concentration of only one reactant and is independent of others. Decomposition of nitrogen pentoxide in the gas phase as well in an organic solvent like $\mathrm{CCl}_{4}$, conversion of N-chloroacetanilide into pchloroacetanilide, hydrolysis of methyl acetate and inversion of cane sugar, the radioactive disintegration of unstable nuclei are the best examples of first order reactions. Chambre and Young (1958) analyzed a first order chemical reaction in the neighborhood of a horizontal plate. Kandasamy (2002) studied heat and mass transfer effects on a non-linear boundary layer flow with thermal stratification and thermal diffusion in the presence of a chemical reaction. Das et al. (1994) studied the effect of a homogeneous first order chemical reaction on the flow past an impulsively started infinite vertical plate with uniform heat flux and mass transfer. Again, mass transfer effects on a moving isothermal vertical plate in the presence of a chemical reaction were studied by

\footnotetext{
* To whom correspondence should be addressed
} 
Das et al. (1999). Muthucumaraswamy and Velmurugan (2013) studied a parabolic started isothermal vertical plate with uniform mass diffusion, in the presence of a homogeneous chemical reaction of first order. The dimensionless governing equations were solved by the usual Laplace-transform technique.

Natural convection on a flow past a linearly accelerated vertical plate in the presence of viscous dissipative heat using the perturbation method was studied by Gupta et al. (1979). Kafousias and Raptis (1981) extended this problem to include mass transfer effects subjected to variable suction or injection. Soundalgekar (1982) studied the mass transfer effects on flow past a uniformly accelerated vertical plate. Mass transfer effects on a flow past an accelerated vertical plate with uniform heat flux were analyzed by Singh and Singh (1983). Free convection effects on a flow past an exponentially accelerated vertical plate were studied by Singh and Naveen Kumar (1984). The skin friction for an accelerated vertical plate was studied analytically by Hossain and Shayo (1986). Mass transfer effects on an exponentially accelerated infinite vertical plate with constant heat flux and uniform mass diffusion were studied by Basant Kumar Jha et al. (1991). Agrawal et al. (1998) studied free convection due to thermal and mass diffusion in a laminar flow of an accelerated infinite vertical plate in the presence of the magnetic field. Agrawal et al. (1999) further extended the problem of an unsteady free convective flow and mass diffusion of an electrically conducting elasto-viscous fluid past a parabolic starting motion of the infinite vertical plate with a transverse magnetic plate. Recently, Muthucumaraswamy and Lakshmi (2013) studied thermal radiation effects on a flow past a parabolic started isothermal vertical plate with variable mass diffusion. The governing equations are tackled using the Laplace transform technique.

It is proposed to study the effects of a flow past an infinite vertical plate subjected to parabolic motion with variable temperature and mass diffusion, in the presence of a chemical reaction of first order. The dimensionless governing equations are solved using the Laplace-transform technique. The solutions are in terms of exponential and complementary error function. The study of parabolic heating is found useful in solar collectors (Brooks et al., 2006) and solar cooking (Murthy et al., 2007). It is also found useful in nuclear engineering, e.g. in radioactive disintegration of unstable nuclei (Agrawal, 1990).

\section{Mathematical analysis}

An unsteady flow of a viscous incompressible fluid past an infinite isothermal vertical plate with variable temperature and variable mass diffusion, in the presence of a chemical reaction of first order has been considered. The $x^{\prime}$-axis is taken along the plate in the vertically upward direction and the $y$-axis is taken normal to the plate. At time $t^{\prime} \leq 0$, the plate and the fluid are at the same temperature $T_{\infty}$ and concentration $C_{\infty}^{\prime}$. At time $t^{\prime}>0$, the plate is started with a velocity $u=u_{0} \cdot t^{\prime 2}$ in its own plane against the gravitational field and the temperature from the plate is raised to $T_{w}$ and the concentration level near the plate is also raised to $C_{w}^{\prime}$. A chemically reactive species which transforms according to a simple reaction involving the concentration is emitted from the plate and diffuses into the fluid. A chemically reactive species which transforms according to a simple reaction involving the concentration is emitted from the plate and diffuses into the fluid. The reaction is assumed to take place entirely in the stream. Then under usual Boussinesq's approximation for the unsteady parabolic starting motion is governed by the following equations

$$
\begin{aligned}
& \frac{\partial u}{\partial t^{\prime}}=g \beta\left(T-T_{\infty}\right)+g \beta^{*}\left(C^{\prime}-C_{\infty}^{\prime}\right)+v \frac{\partial^{2} u}{\partial y^{2}}, \\
& \rho C_{p} \frac{\partial T}{\partial t^{\prime}}=k \frac{\partial^{2} T}{\partial y^{2}} \\
& \frac{\partial C^{\prime}}{\partial t^{\prime}}=D \frac{\partial^{2} C^{\prime}}{\partial y^{2}}-k_{l}\left(C^{\prime}-C_{\infty}^{\prime}\right)
\end{aligned}
$$


with the following initial and boundary conditions

$$
\begin{aligned}
& u=0, \quad T=T_{\infty}, \quad C^{\prime}=C_{\infty}^{\prime} \quad \text { for all } \quad y, t^{\prime} \leq 0, \\
& t^{\prime}>0: u=u_{0} \cdot t^{\prime 2}, \quad T=T_{\infty}+\left(T_{w}-T_{\infty}\right) A t^{\prime}, \\
& C^{\prime}=C_{\infty}^{\prime}+\left(C_{w}^{\prime}-C_{\infty}^{\prime}\right) A t^{\prime} \quad \text { at } \quad y=0, \\
& u \rightarrow 0 \quad T \rightarrow T_{\infty}, \quad C^{\prime} \rightarrow C_{\infty}^{\prime} \quad \text { as } \quad y \rightarrow \infty \\
& \text { where } \quad A=\left(\frac{u_{0}{ }^{2}}{v}\right)^{1 / 3} \text {. }
\end{aligned}
$$

On introducing the following non-dimensional quantities

$$
\begin{aligned}
& U=u\left(\frac{u_{0}}{v^{2}}\right)^{1 / 3}, \quad t=\left(\frac{u_{0}^{2}}{v}\right)^{1 / 3} t^{\prime}, \quad Y=y\left(\frac{u_{0}}{v^{2}}\right)^{1 / 3}, \quad \theta=\frac{T-T_{\infty}}{T_{w}-T_{\infty}}, \quad C=\frac{C^{\prime}-C_{\infty}^{\prime}}{C_{w}^{\prime}-C_{\infty}^{\prime}}, \\
& \mathrm{Gr}=\frac{g \beta\left(T-T_{\infty}\right)}{\left(v \cdot u_{0}\right)^{1 / 3}}, \quad \mathrm{Gc}=\frac{g \beta\left(C^{\prime}-C_{\infty}^{\prime}\right)}{\left(v \cdot u_{0}\right)^{1 / 3}}, \quad K=K_{l}\left(\frac{v}{u_{0}^{2}}\right)^{\frac{1}{3}}, \quad \operatorname{Pr}=\frac{\mu C_{p}}{k}, \quad \mathrm{Sc}=\frac{v}{D}
\end{aligned}
$$

Eqs (2.1) to (2.3) reduce to the following dimensionless form

$$
\begin{aligned}
& \frac{\partial U}{\partial t}=\operatorname{Gr} \theta+\operatorname{Gc} C+\frac{\partial^{2} U}{\partial Y^{2}}, \\
& \frac{\partial \theta}{\partial t}=\frac{1}{\operatorname{Pr}} \frac{\partial^{2} \theta}{\partial Y^{2}} \\
& \frac{\partial C}{\partial t}=\frac{1}{\operatorname{Sc}} \frac{\partial^{2} C}{\partial Y^{2}}-K C .
\end{aligned}
$$

In Eq.(2.8) the negative sign indicates that the reaction normally takes place from higher concentration level to lower concentration level.

The corresponding initial and boundary conditions in a dimensionless form are as follows

$$
\begin{aligned}
& U=0, \quad \theta=0, \quad C=0 \quad \text { for all } \quad Y, t \leq 0, \\
& t>0: \quad U=t^{2}, \quad \theta=t, \quad C=t \quad \text { at } \quad Y=0, \\
& U \rightarrow 0, \quad \theta \rightarrow 0, \quad C \rightarrow 0 \quad \text { as } \quad Y \rightarrow \infty .
\end{aligned}
$$


The dimensionless governing Eqs (2.6) to (2.8) and the corresponding initial and boundary conditions Eq.(2.9) are tackled using the Laplace transform technique.

$$
\begin{aligned}
& \theta=t\left[\left(1+2 \eta^{2} \operatorname{Pr}\right) \operatorname{erfc}(\eta \sqrt{\operatorname{Pr}})-\frac{2 \eta \sqrt{\operatorname{Pr}}}{\sqrt{\pi}} \exp \left(-\eta^{2} \operatorname{Pr}\right)\right], \\
& C=\frac{t}{2}[\exp (2 \eta \sqrt{\operatorname{Sc} K t}) \operatorname{erfc}(\eta \sqrt{\mathrm{Sc}}+\sqrt{K t})+\exp (-2 \eta \sqrt{\operatorname{Sc} K t}) \operatorname{erfc}(\eta \sqrt{\mathrm{Sc}}-\sqrt{K t})]+ \\
& -\frac{\eta \sqrt{\mathrm{Sc}} \sqrt{t}}{2 \sqrt{K}}[\exp (-2 \eta \sqrt{\mathrm{Sc} K t}) \operatorname{erfc}(\eta \sqrt{\mathrm{Sc}}-\sqrt{K t})+ \\
& -\exp (-2 \eta \sqrt{\operatorname{Sc} K t}) \operatorname{erfc}(\eta \sqrt{\mathrm{Sc}}+\sqrt{K t})] \\
& U=\frac{(2-b) t^{2}}{6}\left[\left(3+12 \eta^{2}+4 \eta^{4}\right) \operatorname{erfc}(\eta)-\frac{\eta}{\sqrt{\pi}}\left(10+4 \eta^{2}\right) \exp \left(-\eta^{2}\right)\right]+ \\
& +\frac{b t^{2}}{6}\left[\left(3+12 \eta^{2} \operatorname{Pr}+4 \eta^{4}(\operatorname{Pr})^{2}\right) \operatorname{erfc}(\eta \sqrt{\operatorname{Pr}})-\frac{\eta \sqrt{\operatorname{Pr}}}{\sqrt{\pi}}\left(10+4 \eta^{2} \operatorname{Pr}\right) \exp \left(-\eta^{2} \operatorname{Pr}\right)\right]+ \\
& +2 \operatorname{derfc}(\eta)+2 a d t\left[\left(1+2 \eta^{2}\right) \operatorname{erfc}(\eta)-\frac{2 \eta}{\sqrt{\pi}} \exp \left(-\eta^{2}\right)\right]+ \\
& -d \exp (a t)[\exp (2 \eta \sqrt{a t}) \operatorname{erfc}(\eta+\sqrt{a t})+\exp (-2 \eta \sqrt{a t}) \operatorname{erfc}(\eta-\sqrt{a t})]+ \\
& +d \exp (a t)\left[\begin{array}{l}
\exp (2 \eta \sqrt{\operatorname{Sc}(K+a) t}) \operatorname{erfc}(\eta \sqrt{\mathrm{Sc}}+\sqrt{(K+a) t})+ \\
+\exp (-2 \eta \sqrt{\operatorname{Sc}(K+a) t}) \operatorname{erfc}(\eta \sqrt{\mathrm{Sc}}-\sqrt{(K+a) t})
\end{array}\right]+ \\
& -d(1+a t)[\exp (2 \eta \sqrt{\operatorname{Sc} K t}) \operatorname{erfc}(\eta \sqrt{\operatorname{Sc}}+\sqrt{K t})+\exp (-2 \eta \sqrt{\operatorname{ScK} t}) \operatorname{erfc}(\eta \sqrt{\operatorname{Sc}}-\sqrt{K t})]+ \\
& +\frac{a d \eta \sqrt{\mathrm{Sc}} \sqrt{t}}{\sqrt{K}}[\exp (-2 \eta \sqrt{\mathrm{Sc} K t}) \operatorname{erfc}(\eta \sqrt{\mathrm{Sc}}-\sqrt{K t})+ \\
& -\exp (2 \eta \sqrt{\operatorname{Sc} K t}) \operatorname{erfc}(\eta \sqrt{\mathrm{Sc}}+\sqrt{K t})] \\
& \text { where, } \quad a=\frac{K \mathrm{Sc}}{1-\mathrm{Sc}}, \quad b=\frac{\mathrm{Gr}}{1-\mathrm{Pr}}, \quad d=\frac{\mathrm{Gc}}{2 a^{2}(1-\mathrm{Sc})} \quad \text { and } \quad \eta=\frac{Y}{2 \sqrt{t}} \text {. }
\end{aligned}
$$

\section{Results and discussion}

For a physical understanding of the problem numerical computations are carried out for different physical parameters Gr, Gc, Sc and $t$. The value of the Schmidt number Sc is taken to be 0.6 which corresponds to water-vapor. Also, the values of the Prandtl number Pr are chosen such that they represent air $(\operatorname{Pr}=0.71)$. The numerical values of the velocity are computed for different physical parameters such as the chemical reaction parameter, Prandtl number, thermal Grashof number, mass Grashof number, Schmidt number and time.

The effect of the Schmidt number is important in a chemical reaction. The numerical values of the Schmidt number and the corresponding species are listed in the following table 


\begin{tabular}{|l|l|l|}
\hline Species & Schmidt number $(\mathrm{Sc})$ & Name of the chemical species \\
\hline $\mathrm{H}_{2}$ & 0.16 & hydrogen \\
\hline $\mathrm{He}$ & 0.3 & heleium \\
\hline $\mathrm{H}_{2} \mathrm{O}$ & 0.6 & water vapor \\
\hline $\mathrm{C}_{6} \mathrm{H}_{5} \mathrm{CH}_{2} \mathrm{CH}_{3}$ & 2.01 & ethyl benzene \\
\hline
\end{tabular}

Figure 1 ilustrates the effect of the concentration profiles for different values of the chemical reaction parameter $(K=0.2,2,5,10)$ at $t=0.4$. The effect of the chemical reaction parameter is important in the concentration field. The profiles have the common feature that the concentration decreases in a monotone fashion from the surface to a zero value far away in the free stream. It is observed that the concentration increases with decreasing the chemical reaction parameter. The trend shows that there is a dip in concentration due to a higher intensity of chemical reaction.

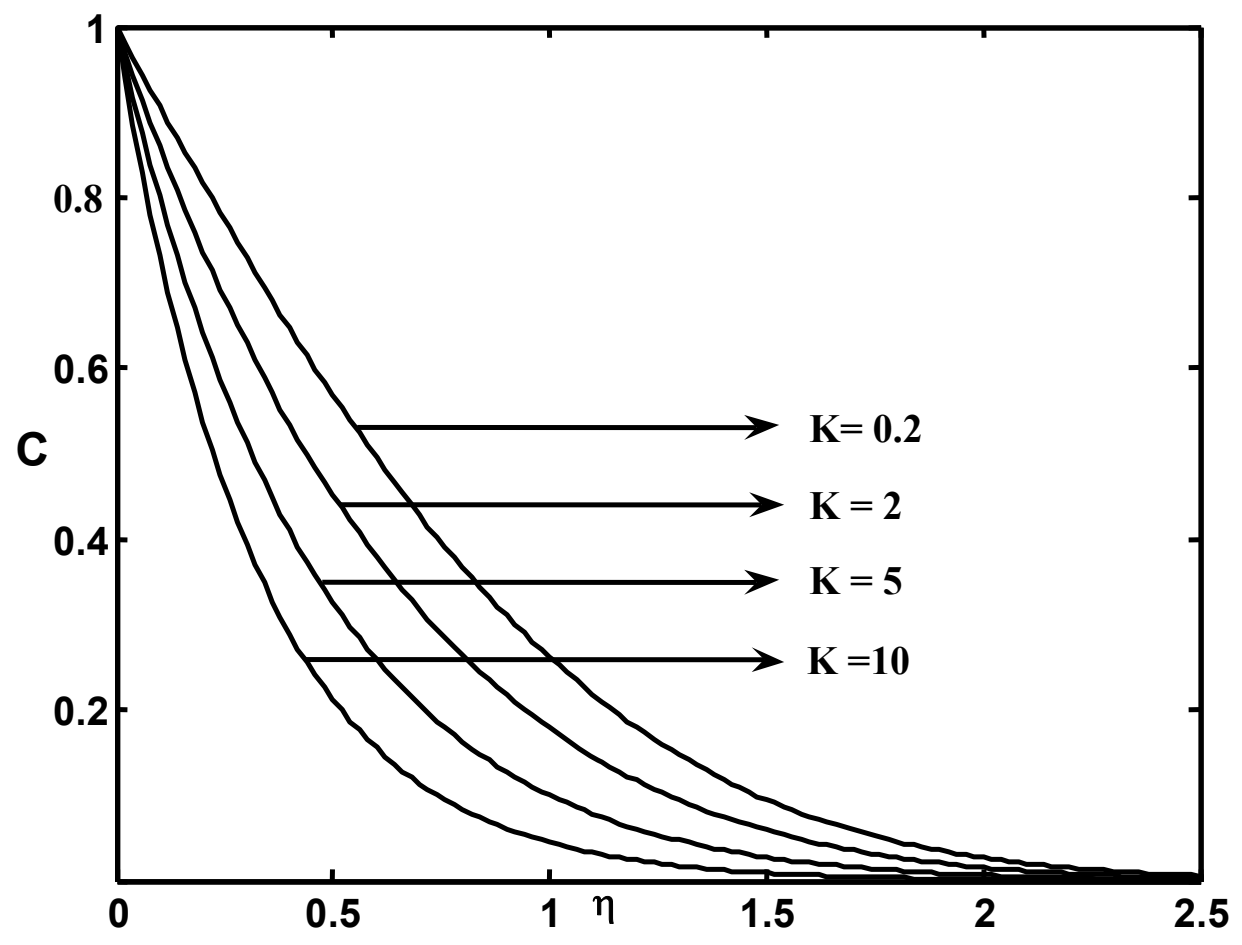

Fig.1. Concentration profiles for different values of $K$.

The velocity profiles for different values of the chemical reaction parameter $(K=0.2,4,8), \mathrm{Gr}=2, \mathrm{Gc}=10, \operatorname{Pr}=0.71$ and $t=0.2$ are shown in Fig.2. It is observed that the velocity increases with decreasing the chemical reaction parameter. Figure 3 demonstrates the effects of different values of the thermal Grashof number $(\mathrm{Gr}=2,5)$, mass Grashof number $(\mathrm{Gc}=5,10), K=2$ and $\operatorname{Pr}=0.71$ on the velocity at $t=0.2$. It is observed that the velocity increases with increasing values of the thermal Grashof number or mass Grashof number. It is also observed that there is a considerable increase in velocity with increasing values of $\mathrm{Gc}$ than $\mathrm{Gr}$. This is due to the presence of a chemical reaction. 


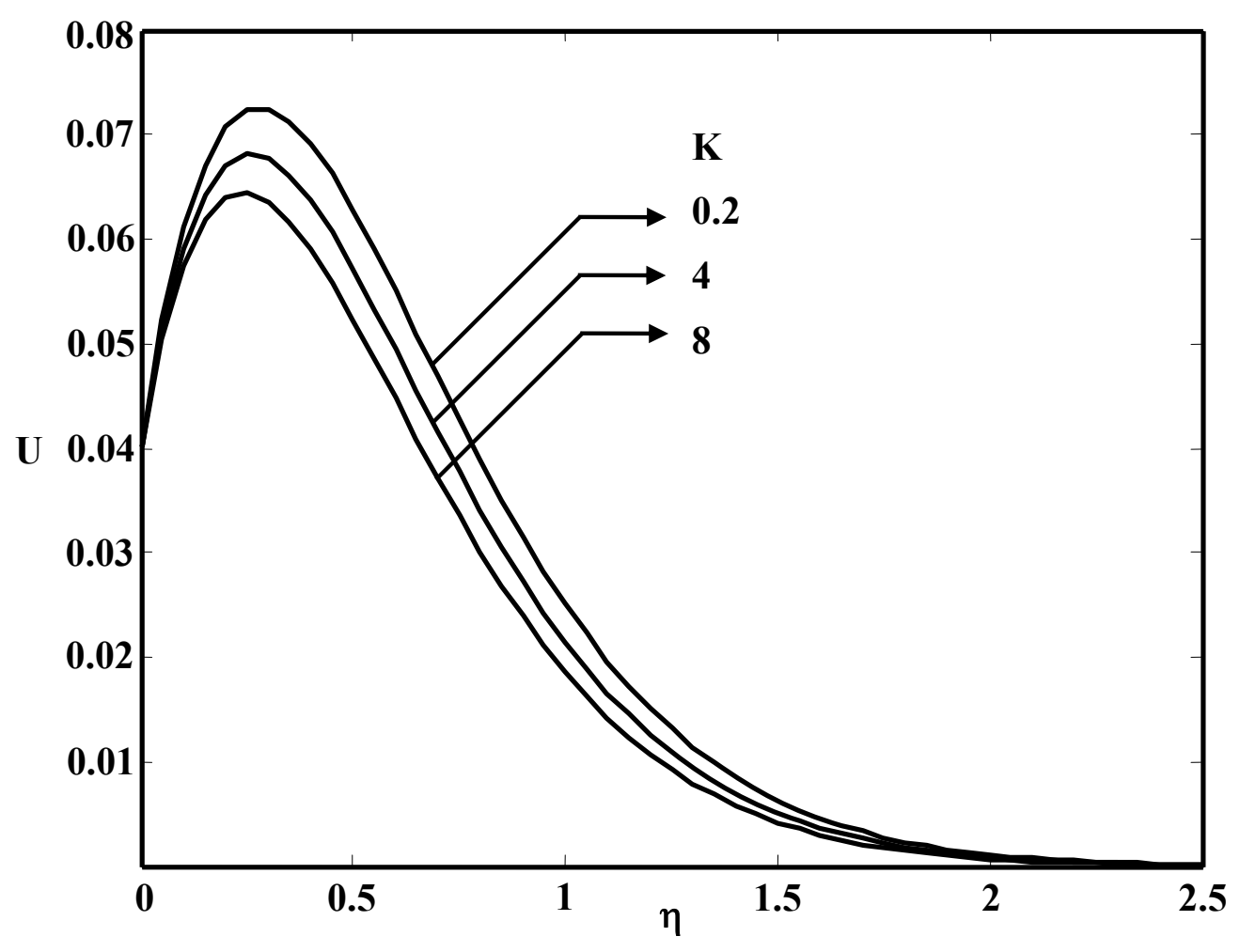

Fig.2. Velocity profiles for different values of $K$.

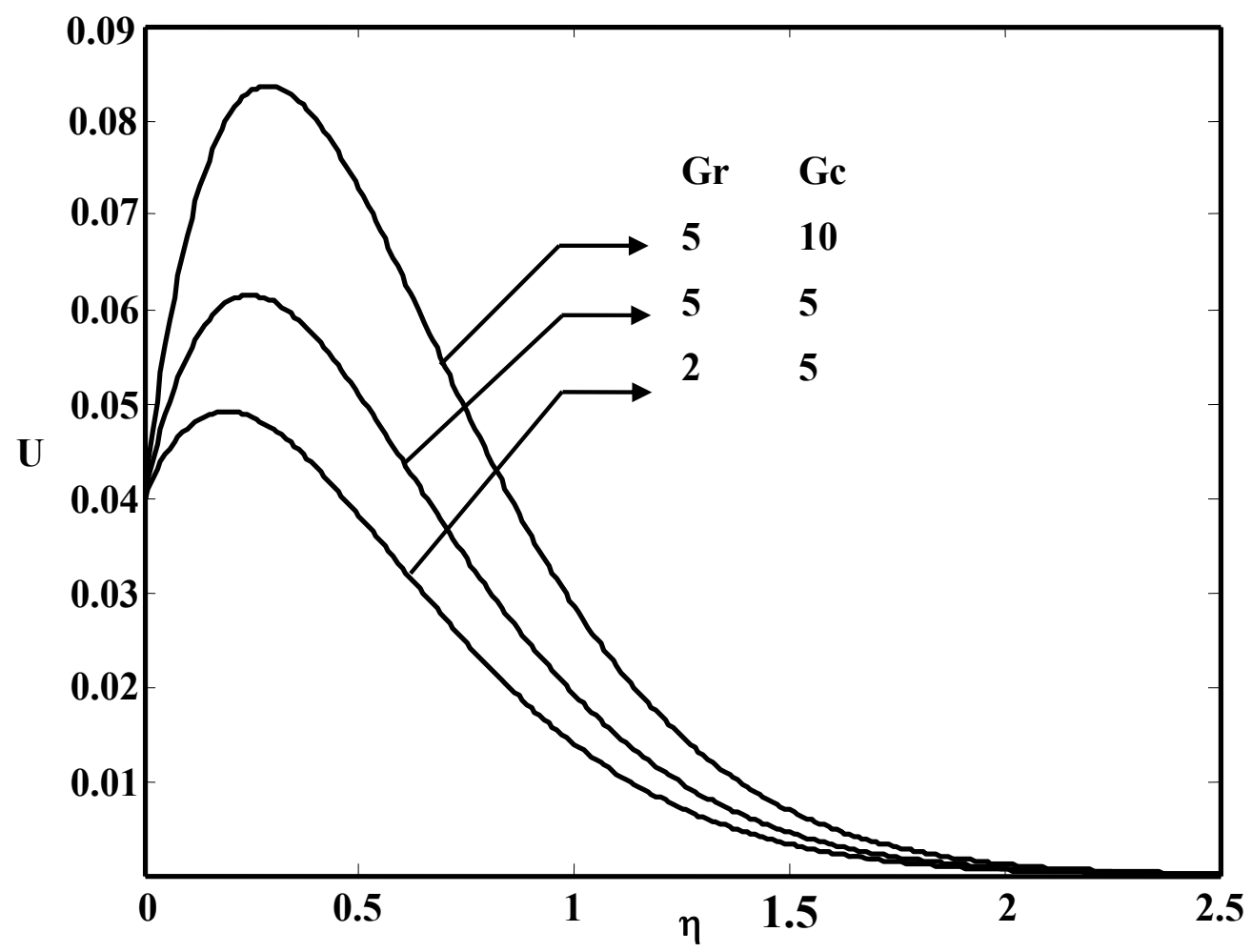

Fig.3. Velocity profiles for different values of Gr and Gc. 


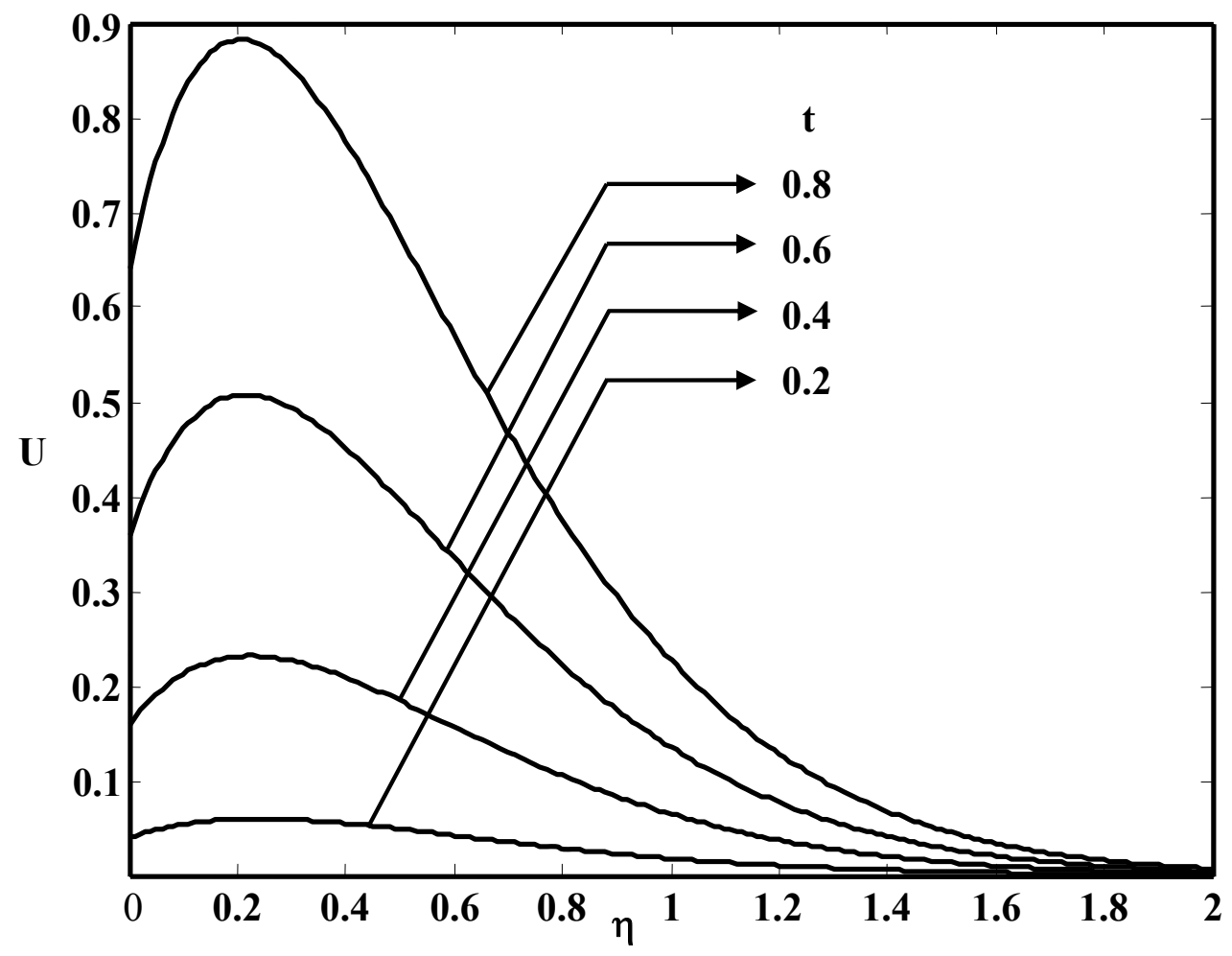

Fig.4. Velocity profiles for different values of $t$.

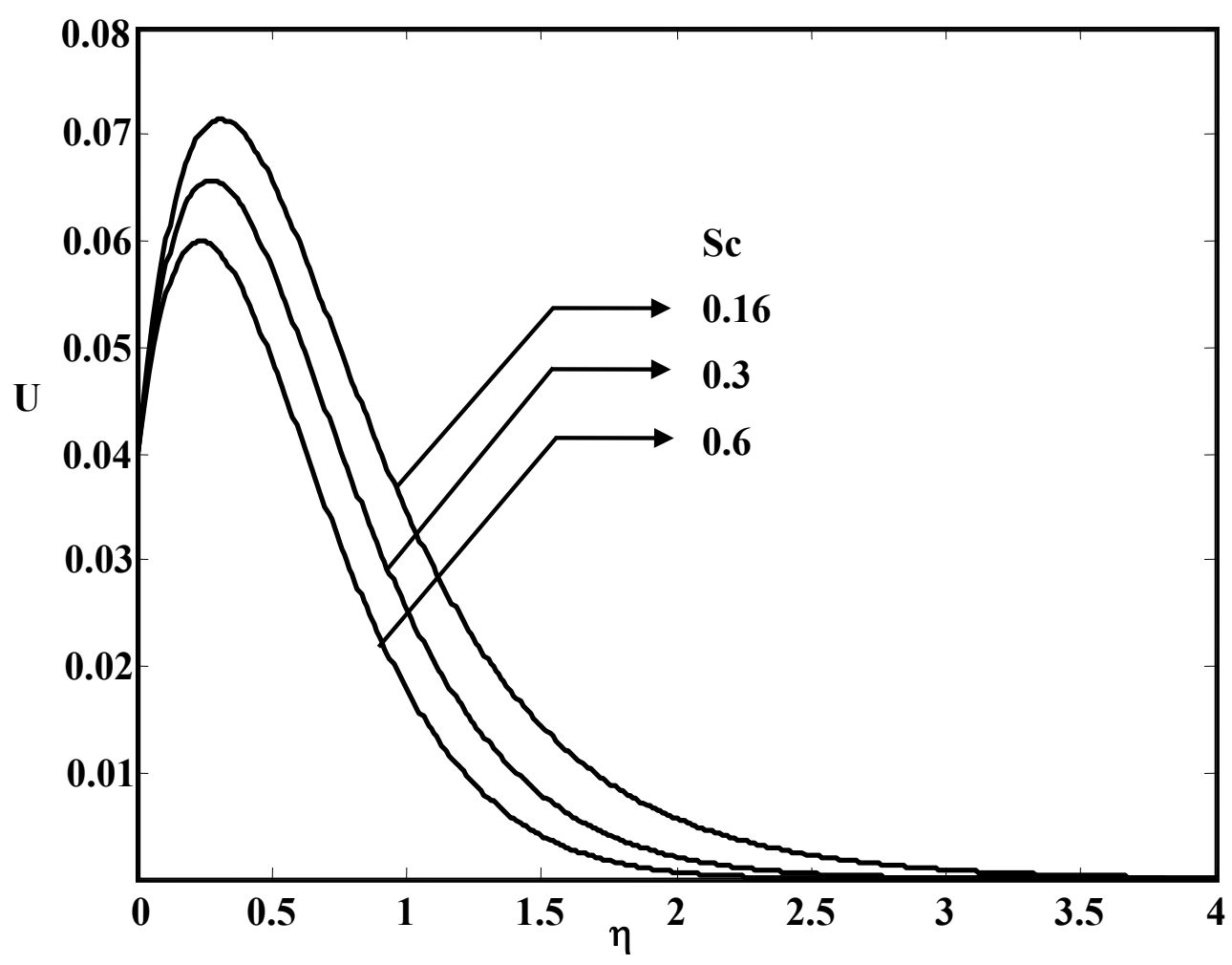

Fig.5. Velocity profiles for different values of Sc. 
The velocity profiles for different values of time $(t=0.2,0.4,0.6,0.8), K=5, \mathrm{Gr}=5$ and $\mathrm{Gc}=5$ are presented in Fig.4. The trend shows that the velocity increases with incrasing values of the time $t$. The effects of velocity profiles for different values of the Schmidt number $(\mathrm{Sc}=0.16,0.3,0.6), \mathrm{Gr}=5, \mathrm{Gc}=5, \mathrm{Pr}=0.71$ and $t=0.2$ are shown in Fig.5. It is observed that the velocity increases with decrasing values of the Schmidt number.

\section{Conclusion}

An exact solution of a flow past a parabolic starting motion of an infinite vertical plate with variable temperature and mass diffusion, in the presence of a chemical reaction of first order has been studied. The dimensionless governing equations are solved by the usual Laplace transform technique. The effect of the temperature, the concentration and the velocity fields for different physical parameters such as the chemical reaction parameter, thermal Grashof number and mass Grashof number are studied graphically. The conclusions of the study are as follows:

(i) The velocity increases with increasing values of the thermal Grashof number or mass Grashof number, but the trend is just reversed with respect to the chemical reaction parameter.

(ii) The temperature of the plate increases with decreasing values of the Prandtl number.

(iii) The plate concentration increases with decreasing values of the chemical reaction parameter.

\section{Nomenclature}

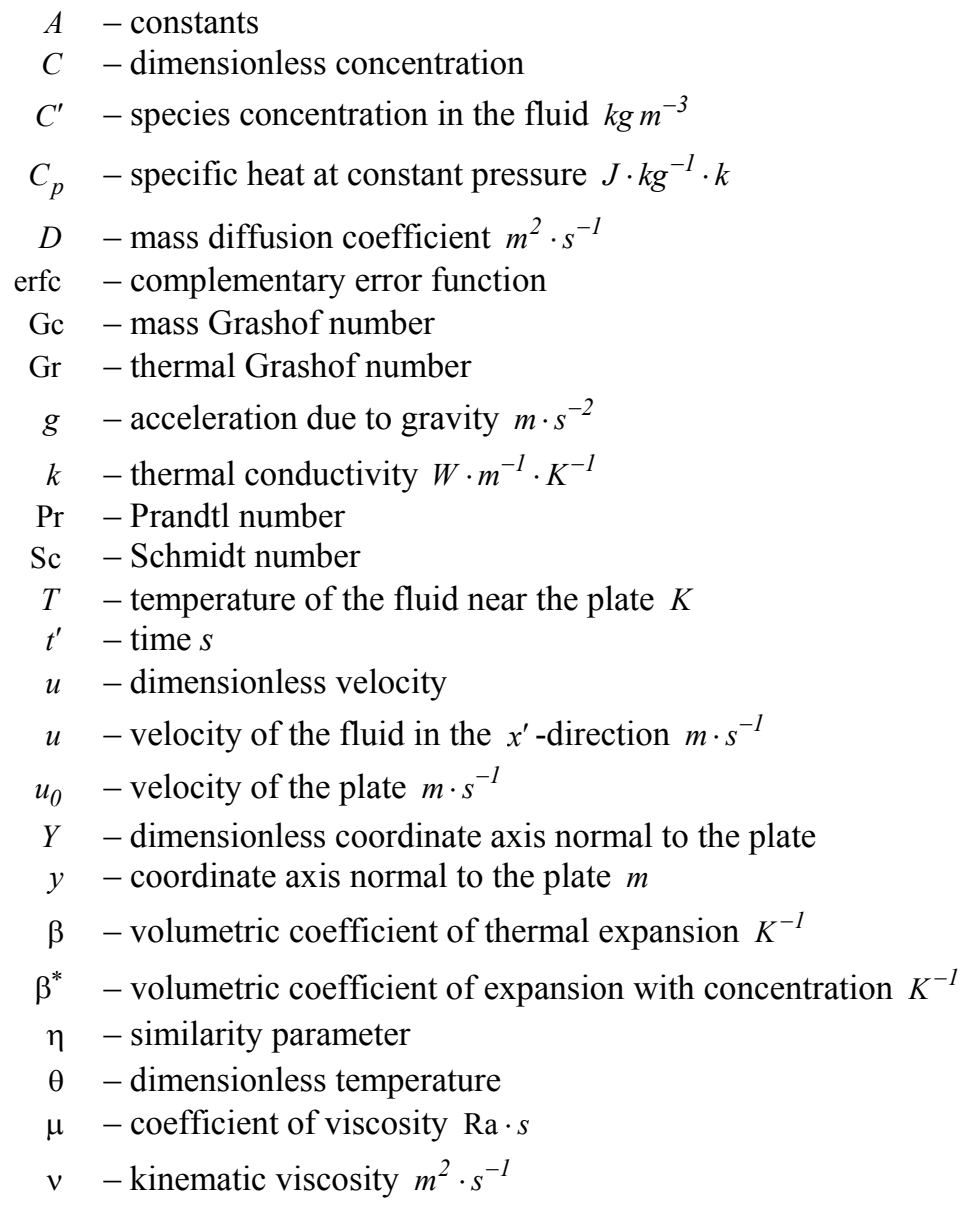


$\rho \quad$ - density of the fluid $\mathrm{kg} \cdot \mathrm{m}^{-3}$

$\tau \quad$ - dimensionless skin-friction $\mathrm{kg} \cdot \mathrm{m}^{-1} \cdot \mathrm{s}^{2}$

\section{Subscripts}

$w$ - conditions at the wall

$\infty \quad$ - free stream conditions

\section{References}

Agrawal A.K., Samria N.K. and Gupta S.N. (1998): Free convection due to thermal and mass diffusion in laminar flow of an accelerated infinite vertical plate in the presence of magnetic field. - Journal of Heat and Mass Transfer, vol.20, pp.35-43.

Agrawal A.K., Samria N.K. and Gupta S.N. (1999): Study of heat and mass transfer past a parabolic started infinite vertical plate. - Journal of Heat and Mass Transfer, vol.21, pp.67-75.

Agrawal G.L. (1990): Basic Chemical Kinetics. - NewDelhi: Tata McGraw-Hill Publishing Company Limited.

Basanth K.J., Prasad R. and Surendra R. (1991): Mass transfer effects on the flow past an exponentially accelerated vertical plate with constant heat flux. - Astrophysics and Space Science, vol.181, pp.125-134.

Brooks M.J., Mills I. and Harms T.M. (2006): Performance of a parabolic trough solar collector. - Journal of Energy in South Africa, vol.17, pp.71-80.

Chambre P.L. and Young J.D. (1958): On the diffusion of a chemically reactive species in a laminar boundary layer flow. - The Physics of Fluids, vol.1, pp.48-54.

Das U.N., Deka R.K. and Soundalgekar V.M. (1994): Effects of mass transfer on flow past an impulsively started infinite vertical plate with constant heat flux and chemical reaction. - Forschung im Ingenieurwesen, vol.60, pp.284-287.

Das U.N., Deka R.K. and Soundalgekar V.M. (1999): Effects of mass transfer on flow past an impulsively started infinite vertical plate with chemical reaction. - The Bulletin of Guma, vol.5, pp.13-20.

Gupta A.S., Pop I. and Soundalgekar V.M. (1979): Free convection effects on the flow past an accelerated vertical plate in an incompressible dissipative fluid. - Rev. Roum. Sci. Techn. Mec. Apl., vol.24, pp.561-568.

Hossain M.A. and Shayo L.K. (1986): The skin friction in the unsteady free convection flow past an accelerated plate. Astrophysics and Space Science, vol.125, pp.315-324.

Kafouias N.G. and Raptis A.A. (1981): Mass transfer and free convection effects on the flow past an accelerated vertical infinite plate with variable suction or injection. - Rev. Roum. Sci. Techn.-Mec. Apl., vol.26, pp.1122.

Kandasamy R. (2002): Effects of chemical reaction, heat and mass transfer on nonlinear boundary layer flow with thermal stratification and thermal diffusion in the presence of suction. - Journal of Energy, Heat and Mass Transfer, vol.24, pp.223-233.

Murthy V.V.S., Gupta A., Mandloi N. and Shukla A. (2007): Evaluation of thermal performance of heat exchanger unit for parabolic solar cooker for off-place cooking. - Indian Journal of Pure and Applied Physics, vol.45, pp.745-748.

Muthucumaraswamy R. and Lakshmi V. (2013): On flow past a parabolic started isothermal vertical plate with variable mass diffusion in the presence of thermal radiation. - Annals of Engineering Hunedoara, vol.XI, pp.227230. 
Singh A.K. and Singh J. (1983): Mass transfer effects on the flow past an accelerated vertical plate with constant heat flux. - Astrophysics and Space Science, vol.97, pp.57-61.

Singh A.K. and Naveen K. (1984): Free convection flow past an exponentially accelerated vertical plate. Astrophysics and Space Science, vol.98, pp.245-258.

Soundalgekar V.M. (1982): Effects of mass transfer on the flow past an accelerated vertical plate. - Letters in Heat and Mass Transfer, vol.9, pp.65-72.

Received: August 3, 2013

Revised: September 11, 2013 